\title{
DISCOURSE IN VIRTUAL CROSS-CULTURAL COMMUNICATION: A DIALOGUE OF CULTURES OR A CLASH OF MENTALITIES? (A CASE STUDY RESEARCH IN EFL EDUCATION IN RUSSIA)
}

\author{
A.L. Nazarenko \\ Moscow State University (Moscow, Russia). \\ E-mail: anazarenkoster@gmail.com
}

\begin{abstract}
This paper presents a case study research based on the experience of Moscow State University of using cross-cultural telecommunication projects as a "testing ground" for developing students' cross-cultural communicative competence. This competence was assessed in terms of success / failure of cross-cultural interaction. The transcripts of forums and chats have been analyzed as well as the results of the survey of studentsparticipants, aimed at getting their opinion about the project ("student satisfaction" factor).
\end{abstract}

Keywords: telecommunication projects; cross-cultural communication; success / failure of cross-cultural communication.

\section{Introduction}

In a virtual environment as well as in a real one, the discourse "has a lot of dimensions" and takes place in various spheres of human activity with different and various purposes [1]. In the field of education, which adopted and adapted information technologies for its needs, a new form of learning in the virtual environment was introduced: distance learning or online e-learning, involving - similar to a traditional face-to-face format - "interactive activity of the communicants, establishing and maintaining a contact, emotional and informative exchange, mutual influencing, intertwining of instantly changing communicative strategies and their verbal and non-verbal implementation in communication" [Ibid: 5227], i.e. a specific didactic discourse. The analysis of this discourse is a sui generis diagnostics of learning efficacy.

One of the areas of education, especially important in a contemporary multicultural world, is cross-cultural communication, aimed at the development of cross-cultural communicative competence including achieving understanding, tolerance and respect of other cultures. Cross-cultural competence is directly associated with the notion of culturally-conditioned communicative competence, which determines success or failure of cultural interaction. The term "crosscultural communication" refers to cases when communicative competences are so different that it affects the outcome of the communicative event and actually eliminates the possibility of understanding" [2]. 
In contemporary science there are two polar viewpoints concerning the issue of understanding between different cultures. According to one, understanding in cross-cultural communication is possible and necessary. The other states that it is impossible in principle, because cultures are "closed entities", each of them being a "thing-in-itself" [3: 46].

However, cross-cultural communication as theory and practice continues to exist and develop and, due to the progress of information and telecommunication technologies, its sphere has extended by now far beyond real communication and more and more is being realized at all levels in a virtual space. The study of this phenomenon could provide some additional evidence for clarifying the abovementioned issue of achieving understanding [and acceptance] in cross-cultural communication.

\section{Methodology}

\section{The outline of the local educational situation}

The use of the latest telecommunication technologies (videoconferencing with a visual contact of communicants, in particular) makes it possible to conduct cross-cultural educational projects, which could serve as "a testing ground" for applying theoretical postulates of the discipline of CrossCultural Communication to practice in conditions imitating real crosscultural interaction.

Thus, future specialists have the possibility and opportunity to prepare themselves and to test their readiness to meet the challenges of the multicultural world in which they will have to live and work.

That is why the MSU Faculty of Foreign Languages and Area Studies has been participating in telecommunication projects with foreign universities for more than 10 years.

The "Global Understanding" course is a worldwide cross-cultural university project via videoconferencing, initiated by East Carolina University (NC, USA) and now involving about 50 universities from more than 30 nations. It is aimed at students "meeting" their partners from different countries to learn from them about their native cultures. This sort of socio-cultural knowledge is believed to be extremely important for understanding the specifics of other cultures and, therefore, for successful communication in a global world community [4].

Another project "Russian Culture via Films" with Slippery Rock University (PA, USA) was based on both Russian and American students watching selected Russian films and then discussing them in terms of specific traits of the Russian national character depicted in them. 


\section{Data collection method}

A "students' satisfaction" factor was taken as a parametre of indirect assessment of the success / failure of cross-cultural communication, with the assumption that logically students cannot "be happy" if their communication with peers was unsuccessful. To find out whether the students were contented with their cross-cultural experience of communicating with their partners in the project, they were asked to fill in a special questionnaire.

Another approach was concerned with a written discourse of virtual communication in the telecommunication projects. Taking into account that the analysis of a didactic discourse in a virtual space is, in a sense, a diagnostic tool, the attempt was made to consider the experience of two projects ("Russian Culture via Films" and "Global Understanding") through the prism of discourse, to analyze the transcripts of the forums and chats and to interpret results obtained in terms of "success-failure" in developing students' cross-cultural communication.

\section{Discussion of the results}

In the questionnaire the students answered the following questions:

1. What did you find particularly interesting in the GU project?

2. What did you find out from communicating with representatives of foreign languages and cultures that you had never heard of before?

3 . What did the project give to you in terms of mastering crosscultural communication?

It was answered by 34 respondents who had communicated with their partners via videoconference. All of them highly assessed the project, its informative and enlightening value and its influence on them personally.

Here are some sample answers:

1. Polina: It was very interesting for me to find out about the cultures of different countries, and the world outlook of people from cultures other than ours.

Aida: New people, new acquaintances! Lots of new and unusual things which at first I couldn't grasp, but which I then understood to some extent.

Alyona: To express your own point of view, to listen to native speakers, "to open up new countries".

Lilia: Everything was absolutely new, and therefore interesting. Every class was like discovering a new world.

Polina: To understand that, although we live in different corners of the world, we have more in common than differences.

Elizaveta: It was interesting to learn each time that, in spite of differences in regions, culture and languages, we - teenagers - have similar interests, pastimes and endless plans for the future.

2. Yevgenia: I didn't know that in America people made New Year resolutions.

Vladislava: I found out that a lot of people in America are interested in Russia. Also I learned lot of interesting things about the system of education in Peru. 
Aida: I was struck by the stories of Peruvian healers living in the forest and using morphine in treating patients.

David: Practically everything in Peru's culture was new to me, but I was particularly struck by the annual festival when Peruvians throw "water balls" at each other, similar to our snowballing - but, unlike us, they throw them at strangers, who don't object.

Polina: I've abandoned my stereotypes of America and Peru. For example I understood that Americans don't consider money to be the most important thing, but that family, friends and love are more important for them. I also learned that we and Peruvians have similar holidays and a similar education system.

Significantly, almost all students touched upon the question of stereotypes, in all cases evaluating them negatively, as misconceptions which need to be dropped since they impede unbiased relations and open communication.

Eugene: My attitude towards Americans has changed. I understood that one should not judge a person or a whole nation only by stereotypes. Our task is to break false stereotypes by communicating directly.

Vlada: The most interesting thing was to talk about stereotypes and to find out what foreigners think about Russia.

Eliza: I didn't like Americans' stereotypes about Russia.

Aida: Only by communicating with foreigners do you understand how little you know about their culture. For example, what did I know about Peru and Peruvians before communicating with them? Nothing! I only had a definite stereotype: I imagined them always lying on the beach, doing nothing. But I found out that this country is trying to attain a higher standard of living, similar to that of developed countries and is putting a lot of effort into this, especially in the fields of education, medicine, etc.

We couldn't understand what was behind that immutable American smile, but our (already) friends from the USA explained to us why each of them always has an expression of happiness.

The assessment of personal usefulness and the humanitarian value of the project were very high:

3. Lilia: "This project gave me a wonderful opportunity to learn how people in different countries with different cultures live, to learn about their perception of life. And also to understand them. Thanks a lot for this possibility. Now I have friends with whom I can talk about many things and all the time learn something new.

Personally I have understood that people, living in different parts of the world, are not so much different from us. A lot of their opinions, thoughts and vision of things are close to mine and now I, think, I can go to their country without being afraid that I would not be understood. Now I do want to get in touch with a different culture and to get to know it even more and better. Projects of such sort unite people and help maintain mutual understanding among representatives of various and different cultures".

Aida: "The project gave me a lot of positive emotions and, certainly, practical knowledge. A lot of new and useful information which could help in future, new friends, broken stereotypes... Global Understanding was invented just for this purpose!

We could talk to native speakers (Americans), discover something we read in newspapers and books about, saw on TV but never faced in real life. I mean culture, traditions religions of other nations and peoples".

Polina: "Global Understanding Project helps overcome not only language but also cultural barrier". 
Anna: "The Project helps understand similarity of various cultures (the attitude to law in Russia and Peru), brings people closer, breaks negative stereotypes (both of Russian and American students)".

Interestingly, the word "friends" was used by several students in the survey. In our opinion this is a very significant factor, meaning that the project reached its goal - understanding between people. Because a friend can only be a person who you know, understand and trust.

The analysis of the transcripts of seven forums (from both "Global Understanding" and "Russian Culture via Films") showed, in greater or smaller degree, that the vector of the discussions was pointing to some consensus in views. Below is a transcript of a discussion started with a theme formulated by the American professor.

Russian cultural traits via film:

At first glace the films "Tsar Sultan" and "Andrey Rublev" seem literally worlds apart in terms of settings, themes, characters, and mood. However, the more one discusses these films the more one realizes how each film, though totally different, portrays similar characteristics about Russian culture, aspirations, conflicts, as well as Russia's complex realities. Discuss how each film portrays these elements.

Brian: I feel that both movies were more similar to each other than different. I sort of felt the same mood and settings with both films. Whenever the Tsar in Tsar Sultan began to play Pattycake I just lost all faith in that guy. I don't know if they were doing drugs in the castle or what but he seemed a little bit too far out there to be considered a stable leader. The people in Rublev just got taken over by the Mongols and just had to accept it. The people of both films were lost with little guidance. The Tsars just seemed never to be able to do anything. In retrospect to both films the characters seemed to be the same. There was just a lot more happiness in Tsar Sultan but that was due to the singing. The films taught me a lot but if you understand Russian culture then both films portray what is already known very vividly and directly.

Bradley: ...the people seem very down and unhappy. Their spirits changed when they are given the job to help build the bell for their leader. This makes them happy that they are doing something for someone who they admire so much. It seems that the russian people feel comfortable with someone ruling and watching over them and their country.

Wojciech: What struck me the most in both of the movies was the portrayal of the ones with power in Russia. The western concepts of democracy or even the "enlightened autocracy" simply do not apply over there. All the people who possess any sort of authority over others, become autocratic rules, governing without any consent of their people, without even seeking any consent. The rulers of Russia are withdrawn from the society, separated from the "normal" way of living and therefore unable to comprehend and to improve the lives of the common people. They are ruthless rulers, surrounded by bad advisors, whose decisions turn the lives of numerous people into misery. There is no cooperation and integrity within the society and the country as a whole is unable not only to fight off the enemies, but also to develop economically. By concentrating virtually all the powers in the hands of a poor leader dooms the country's outlooks for the future. And this is true until today.

Olga (Russian): To be sincere, I am a little bit surprised by the messages I've read. Personally, I wouldn't limit the discussion to the theme of autocratic rules. I think that the theme of the film is primarily and mainly about the inner world of the Artist, the evolution of his world understanding. It also provoked me to think about the idea of true friendship and betrayal, about the complexity of medieval world in which paganism and christian believes 
mingled. Besides, inspiration and the beauty of labour are very important concepts of Russian culture that should be taken in consideration. I'll be very interested in any ideas about all mentioned.

Elvira (Russian): I don't think that the discussion can be reduced to the problem of the people and the authorities. I dare to say that all Tarkovsky's films are devoted to the development of human personality, to the problem of aesthetic choice. By the way, at the time of Rublev there was no main ruler in Russia. Instead there were plenty of small "provinces" ruled by local leaders who constantly fought against each other. The main character of the film is evidently Rublev, and the whole story from my point of view is the way of an artist, and in the Russian tradition the artist is an embodiment of folk spirit. Here we see how Rublev enters the "real" life, how difficult it is for him to accept everything he sees and how his views on the religion and on the people change. I'd be glad to receive some responses on these aspects.

Bret Elvira: First of all... I would like to thank you for participating in this blackboard discussion. It is so nice to be able to communicate with people from Russia. All of your comments are very interesting to me. I found it interesting to say that Tarkovshy's films address "the problem of aesthetic choice". Even though I have studied Russian culture for a while now, I am still not familiar with this problem in Russian culture. Do you mean that Russians have a problem in choosing a type of beauty? Or is the problem choosing beauty over something that is more practical? I have noticed that Russia will pick the impractical grandiose beautiful method over the simplistic necessity. There seems to be a desire to make things bigger than life... to a point where it could be deemed unnecessary. The problem involving aesthetics in America is that we hold them to be too important. One cannot be famous in America without being the epitome of perfection when it comes to looks. Our children look at the famous people and think that they are what they are supposed to be. Aside from the aesthetic nature of our sexy famous people there is a choice for an aesthetic status in America. Americans aspire to be viewed as perfect by their peers. Everything from buying the right clothes and cars to having the job that impresses everyone on the block... we like to be "better" than everyone else. I am sorry for going off subject. I should have talked more about the movies, but I got carried away. I will stop now that I have noticed how far off topic I went. I just got tangled up in the philosophical implications of what you said and how it pertained to American society. Please explain to me what "the problem of aesthetic choice" means to you and the Russian culture.

Bret D

Subject: A Miracle of the Human Spirit

It seems to me that the forgiveness in the movie Tsar Sultan, shows the spirituality in Russia and how they view human relations. For one to state that Russia is a spiritual nation would be an understatement. It is evident to me that Russia a country with deep religious roots and that this is displayed in these films. Forgiveness is a big part of the Christian religion and seems to be an ability admired by the Russian people. Is it the Christian influence that makes forgiveness an issue in some of their movies or is there something else there in the Russian spirit? I wonder if the Russian people involved with this discussion have any thoughts on forgiveness? Is it an important part of Russian culture? Were you raised to be willing to forgive or told that forgiveness is important while growing up? What do you think about the proverb "forgive and forget?"

Bradley T: I also believe that you have to admire the Russian people and their strong belief in the countries' values. I have only watched the film once, but that was one thing that stood outto me in "Andrey Rublev". Even though things were bad and their country seemed a bit torn the one thing that was not was their spirits. I found that to be very admirable about the Russian people, because many people would make it through tough times like that.

Wojciech: Freedom of the people is, in my opinion, something that the Russian state has always had trouble achieving and to this day really hasn't. Nevertheless the Russian peo- 
ple do join together in times of war and are able to defeat greatest threats to their country posed by foreign powers.

It is noteworthy that in the course of the discussion the positions of the communicants were getting closer and closer: from formal participation meant to present one's point of view irrespective of other participants - to a very interested direct address by name (Elvira) to a participant from another culture group. What is even more remarkable was that the opinions of the American participants changed to quite their opposite due to the interaction with the Russian students, that the existing stereotypes about Russia and Russian people were broken and an unprejudiced vision of "alien" (Russian) culture was achieved. For example, the American students came to understand that Russian people can find happiness not in pleasing their cruel rulers but in expressing themselves in creative work, that they are not passive and gutless (as American students used to think) but are able to pull together all their moral and physical strength in order to withstand disaster and to survive. Such a change of attitude occurred only after the Russian students entered the discussion.

However, complete failures in maintaining cross-cultural dialogue might happen in such projects, which just emphasizes once again the extreme subtlety of the "substance" called "cross-cultural communication" and the need for serious preparation for it. Some fruitful ideas might be derived from thorough study of its discourse peculiarities.

A bad, but at the same time very important experience, was obtained by the Faculty in the course of the abovementioned telecommunication project "Global Understanding". The project itself proved to be a very successful educational initiative: it has constantly been growing due to including new participants as well as extending the content of the educational environment and trying new types and methods of learning. So much more indicative and symptomatic is the failure of communication during one of the chat contacts of two participants from "both ends".

Chats are used together with videoconference, quite often within the same class. In this arrangement half of the student group talk with their partners straight through the screen, the other half, sitting in front of computers with earphones on, use Chat Rooms and work in pairs with their counterparts. They ask them questions about various aspects of their life and culture, clarifying details and extending their knowledge, learning directly from the authentic representatives of this foreign culture.

During one of such links with a Moroccan University a very unpleasant incident took place. The transcript of the chat of two Russian students with their Moroccan interlocutress demonstrates the problem: africa?

$[16: 21]<@$ Tilila $>$ what are the stereotypes that you have about our country or about 
$01[16: 23]<$ MASHA $>$ Africa is hot, very-very hot, as a Finnish guy

[16:24] <Tanya $>$ and, talkingabut stereotypes, it's cannibalism of course))

[16:24]<@Tilila> i'm sorry, can you be more serious because i'm trying to write notes, at the end of the link $i$ have to write a peper about it... so please can you answer to my questions, and i'll answer yours too

$[16: 25]<@$ Tilila $>$ so you think that in africa, there are cannibals?

$[16: 25]<$ Tanya $>$ of course, $u$ eat each other)

[16:26] $<@$ Tilila $>$ no, we don't eat each other!

$01[16: 26]<$ MASHA $>$ mmmm delicious))

[16:26] $<$ Tanya $>$ really? and what do $u$ eat?)

$[16: 26]<@$ Tilila $>$ the same things that you eat in your country...

$[16: 27]<$ Tanya $>$ we eat each other!!!

$[16: 27]<@$ Tilila $>$ girls, be serious!

[16:32] $<@$ Tilila $>$ now, what are the steretypes that you have about us :)

$[16: 33]<$ Tanya $>$ very hot, nerveous people

$[16: 33]<$ Tanya $>$ hot weather i mean

$01[16: 33]<$ MASHA $>$ living in desert

[16:33]<@Tilila $>$ nerveous people, hot weather okay

$[16: 33]<$ Tanya $>$ low level of living, very low

[16:33] $<@$ Tilila $>$ and what do you any idea about our culture and our habits?

$01[16: 34]<$ MASHA $>$ leopard and giraffes in desert

[16:35]<@Tilila $>$ ok, i'll make things more clear, in Morocco there are no giraffes or leopards in desert, we don't have savanas, but we have sahara, with camels...

01[16:35] $<$ MASHA $>$ playing drums and dansing around fire at night

$01[16: 35]<$ MASHA $>$ Eeeeh, camels)

$[16: 35]<@$ Tilila $>$ we don't play drums or dance around fire at night

[16:36] < Tanya $>\mathrm{i}^{\prime} \mathrm{m}$ talking about africa at all, but $\mathrm{i}$ think $\mathrm{u}$ are)

01[16:36] $<$ MASHA $>$ honestly I was in Africa several times but it was Egypt

[16:36] $<@$ Tilila $>$ oh i see, Egypt is a bit different from Morocco :)

$[16: 36]<@$ Tilila $>$ but it's okay

$[16: 37]<$ Tanya $>$ ur behaviour is typical for africa

$[16: 37]<@$ Tilila $>$ are you asking questions or are making deductions?

$01[16: 37]<$ MASHA $>$ what is the difference?

$[16: 37]<$ Tanya $>$ deductions)

$01[16: 38]<$ MASHA $>$ questions

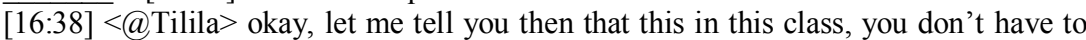
take deductions but to ask questions okay? is obvious

$[16: 38]<@$ Tilila $>$ and the difference between Morocco and the central africa counties

As is clearly seen, the Russian students insulted a Moroccan student on a national basis.

\section{Conclusion}

According to Timoschuk (2010), cross-cultural communication is a means of reducing ethno-confessional tension, a tool for shaping a multicultural society. Its connection to personal knowledge, implicit and explicit layers of culture and also with the role of contemporary society has not been studied enough [5]. Discourse in a social context is defined by some re- 
searchers as a formation, where the participants are "groping" for an adequate language for the description of reality, confirming by this their belonging to a certain semantic cluster, reproducing a collective identity (professional, political, religious and other groups); this is an integrated system including ways of thinking, theoretical system, behavioral practices (underlined by me. - A.N.), cognitive skills, "regulators" of professional activity, etc. [6]. Culture, in its turn, is a set of "codes", which prescribe a human being this or that behaviour, providing in this way "administrative influence" on him / her. Verbal (discoursive) behavior, revealed by the communicants in the quoted case, not at all being prescribed by the rules of Russian national culture and directly contradicting them, can, however, be decoded by foreign participants in communication just like typical, natural, "consecrated" by tradition [7] and therefore extrapolated to the whole culture and leading to failure in communication and confrontation instead of dialogue. In other words, behind each type of discourse there appears its probable world, which helps or hinders the development of cross-cultural communication at implicit and explicit levels [8]. That is why the issue of the possibility of reaching understanding in cross-cultural communication remains open.

Another conclusion is concerned with the specifics of cross-cultural interaction in a virtual space. The results obtained show that all students positively assessed the educational usefulness of the links via videoconferencing (with visual contact). At the same time, links via chat (also synchronous but lacking visual contact) ended up in a failure of communication. It is suggested that during the very first virtual meeting of partners from different cultures there should be a visual contact for them to see each other as real persons, not avatars having no personal characteristics, which they would be tempted to think up by themselves. Though this hypothesis needs verification in experiments with much bigger statistical data, it once again signals the extreme complexity of cross-cultural communication as a phenomenon and the necessity to conduct further research in it, including discourse analysis.

\section{References}

1. Karasik, V. O tipakh diskursa. [About discourse types] (Rus.) Available from: http://ruslang.isu.ru/education/discipline/ philology/disrurs/material/material2 (Accessed: 04.03.2016).

2. Bergelson, M. Mezhkulturnaya kommunikaciya kak issledovatelskaya problema: Lingvisticheskiye metody izucheniya kross-kulturnykh vzaimodeistviy [Intercultural communication as a research issue: Linguistic methods of cross-cultural interaction study]. Moscow State University Journal. Linguistics and Intercultural Communication. 19. (Rus.) Available from: https://www.google.ru (Accessed: 04.03.2016).

3. Yelistratov, V. (2008) Evolyuciya "russkogo mifa" na Zapade. Yazyk. Kultura. Obscheniye. Moscow: Gnozis. p. 45-52.

4. Nazarenko, A., Sizykh, L. \& Fandei, V. (2012) A socio-constructivist approach to enhancing students' learning and participation in the Global Understanding Project. Proceedings of EDULEARN12 4th International Conference on Education and New Learning Technologies 2-4 June 2012. Barcelona, p. 5226-5229. 
5. Timoschuk, E. (2010) Teoriya diskursa i mezhkulturnaya kommunikaciya. INTERCULTUR@L-NET. 9. Available from: http://www.my-luni.ru/journal/clauses/14/ (Accessed: 02.03.2016).

6. Ogurzov, A. Blago i istina: linii raskhozhdeniya $i$ skhozhdeniya. Available from: http://www.philosophy2.ru/iphras/library/wealtrue/ogurzova.html (Accessed: 02.03.2016).

7. Discurs v mezhkulturnoi kommunikacii. Encyclopaedic Dictionary. Available from: http://vocabulary.ru/dictionary/1095/word/diskurs-v-mezhkulturnoi-komunikaci (Accessed: 02.03.2016).

8. Gural, S. (2012) Diskurs-analiz i obucheniye mezhkulturnoi kommunikacii. [Discourseanalysis and teaching intercultural communication]. (Rus.) Available from: http://www.rusnauka.com/36_PVMN_2012/Philologia/7_123980.doc.htm (Accessed: 02.03.2016).

Information about the author:

Nazarenko Alla L., Honorary Professor of Moscow State University, Ph.D., Head of the Department of Linguistics and Information Technology, Faculty of Foreign Languages and Area Studies, Moscow State University (Moscow, Russia). E-mail: anazarenkoster@gmail.com 